\title{
Carabid (Coleoptera) assemblages in the Scottish uplands: the influence of sheep grazing on ecological structure
}

\author{
Lorna J. Cole, Meg L. Pollock, Duncan Robertson, John P. Holland \& David I. McCracken
}

Cole, L. J., Pollock, M. L., Robertson, D., Holland, J. P. \& McCracken, D. I. 2006: Carabid (Coleoptera) assemblages in the Scottish uplands: the influence of sheep grazing on ecological structure. - Entomol. Fennica 17: 229-240.

As a result of the European Community Common Agricultural Policy reform in 2005 it is predicted that livestock grazing in the Scottish uplands will become less intensive. At each of two upland research centres, two large ( $>40 \mathrm{ha}$ ) plots were established to investigate the relationship between grazing intensity in the Scottish uplands and biodiversity. One plot was grazed intensively by sheep while the other was grazed extensively. Ground beetles were sampled by pitfall trapping to determine the influence of grazing pressure on the ecological make-up of ground beetle assemblages. Grazing intensity did not significantly influence carabid diversity. However, grazing intensity, altitude and moisture did influence the carabid ecological assemblage structure at both locations. Large flightless Carabus species were more abundant in extensively managed plots than intensively managed plots at both locations. It is likely that these long-living, relatively immobile beetles were favoured by the greater stability of the vegetation structure in the extensively grazed plots. Monitoring the ecological assemblage structure provides a more sensitive approach than diversity indices when comparing the impact of grazing and agricultural management but is also robust enough to allow direct comparisons between different geographical locations.

L. J. Cole, D. Robertson and D. I. McCracken, Land Economy and Environment Research Group, Scottish Agricultural College, Auchincruive, Ayr, KA65HW, U.

K.; Email: lorna.cole@sac.ac.uk

M. L. Pollack and J. P. Holland, Hill and Mountain Research Centre, Scottish Agricultural College, Kirkton Farm, Crianlarich, FK20 8RU, U. K.

Received 2 November 2005, accepted 26 May 2006

\section{Introduction}

The European Common Agricultural Policy (CAP) has recently been reformed resulting in major changes in the way farming in the EU is supported (Leguen de Lacroix 2003). Subsidies which were previously production orientated (e.g. based on the number of grazing animals), have been replaced by a Single Farm Payment which is determined by historical support payments received by each farm. The link between subsidies and production has consequently broken, and as a result agricultural management will no longer focus simply on maximising production. Consequently, it is predicted that agriculture will become more linked to market demands and that changes in agricultural subsidies will result in, among others, changes in grazing manage- 
ment. In Scotland, it is predicted that grazing intensity in the Scottish uplands will be significantly reduced as a result of the CAP reform (Cook 2004). There is concern that this will have an adverse impact on upland vegetation and the wildlife associated with grazed open habitats.

Changes to livestock grazing practices influence the vegetation structure and composition at both patch and landscape levels and this in turn alters ground beetle assemblages and diversity (Luff \& Rushton 1989, Dennis et al. 1997). Carabid beetles are one of the most common families of surface-active arthropods in the agricultural landscape and are thought to be potential indicators of disturbance, as they are ubiquitous and easily sampled using pitfall traps, are sensitive to environmental factors, and are morphologically and ecologically diverse (Lövei \& Sunderland 1996, Niemelä et al. 2000). These beetles have an important role in the farmland ecosystem, as they are not only important polyphagous predators of a wide range of agricultural pests (Thiele 1977, Lövei \& Sunderland 1996), but also form an important dietary component for many decreasing farmland birds (Holland \& Luff 2000). While monitoring the influence of grazing intensity on the abundance of different species is valuable in its own right (Eyre et al. 1989, Rushton et al. 1989, Purvis et al. 2001), findings at different geographical locations are rarely directly comparable due to differences in the individual species present at each location. Monitoring regimes that focus on the ecological structure of a beetle assemblage are less likely to be sensitive to the requirements of individual species and consequently may be more robust than regimes looking at species composition (Willby et al. 2000). Furthermore, by classifying assemblages on the basis of their ecology we gain a better insight into their ecological functioning (Whittaker 1975) which may in turn help us to predict how an ecosystem will respond to future disturbance (Diaz \& Cabido 1997).

Life-history traits are strongly linked to the frequency of habitat disturbance and large, immobile species with a low fecundity tend to be favoured in undisturbed habitats while small, mobile species with a high fecundity tend to be favoured in disturbed habitats (Southwood 1988). Intensively managed grassland habitats are by nature frequently disturbed, and several studies have shown that large flightless carabids are more abundant in extensively managed habitats (Blake et al. 1994, 1996, Ribera et al. 2001). Changes in grazing pressure and mowing intensity not only affect the disturbance frequency of a habitat but also the vegetation structure and prey availability, which in turn may influence the ecological structure of carabid assemblages. Extensively managed grassland is typically associated with richer, more structurally diverse vegetation when compared to intensively managed grassland (Marriott 2004), and consequently may favour herbivorous carabids such as Harpalus, Bradycellus and Amara species. Intensively managed grassland, on the other hand, has been found to favour Collembola specialists as a result of an increase in prey abundance and a more open vegetation structure facilitating these visually hunting predators (Ribera et al. 2001).

Cole et al. (2002) classified ground beetles into seven ecological groups. The primary objective of the work reported here was to use the ecological groups of Cole et al. (2002) to determine whether grazing pressure in the Scottish uplands influences the ecological make-up of ground beetle assemblages. This study thus focused on the influence of grazing pressure in the Scottish uplands on the ecological structure of carabid assemblages and evaluated the robustness of this approach for monitoring environmental impact at different geographical locations.

\section{Material and methods}

\subsection{Study sites}

Four large ( $>40$ ha) upland grazed plots were established at two Scottish upland research stations: Kirkton (Perthshire) and Sourhope (The Borders). The two research centres were separated by a distance of $184 \mathrm{~km}$. Two adjacent plots at each research station were each allocated to one of two sheep grazing intensities: an extensive light summer-only grazing and an intensive moderate yearround grazing (Table 1). The grazing intensities were set by taking into account the type of forage available in each of the plots. Grazing regimes were started in June 2001 at Kirkton and October 
Table 1. Grazing treatments at the two research centres.

\begin{tabular}{llllll}
\hline Site & Nat. Grid Ref. Plot size & Altitude & Grazing & $\begin{array}{l}\text { Open to } \\
\text { livestock }\end{array}$ \\
\hline Kirkton, Intensive & NN370306 & 44.4 ha & $390-590 \mathrm{~m}$ & $1-2$ sheep ha $^{-1}$ & Jan-Dec \\
Kirkton, Extensive & NN368303 & 40.8 ha & $390-600 \mathrm{~m}$ & $1-1.3$ sheep ha $^{-1}$ & Jun-Oct \\
Sourhope, Intensive & NT846217 & 74.9 ha & $270-470 \mathrm{~m}$ & $3-3.7$ sheep ha $^{-1}$ & Jan-Dec \\
Sourhope, Extensive & NT843211 & 49.7 ha & $260-420 \mathrm{~m}$ & 3 sheep ha ${ }^{-1}$ & Jun-Sep \\
\hline
\end{tabular}

2002 at Sourhope. The aim of the intensive grazing regime was to create a relatively short, homogeneous, less-tussocky sward. The aim of the extensive regime was to create a structurally diverse sward with distinct tussock and inter-tussock areas. A total of 40 locations (i.e., 10 within each plot) were sampled in 2003 and a further 20 locations (i.e., 5 within each plot) were sampled in 2004. Eight of the 2003 locations at Sourhope became encroached with bracken and were consequently relocated in 2004. Sampling locations were chosen to represent the range of altitudes, vegetation types and structures within each plot and were a minimum distance of $8 \mathrm{~m}$ apart.

\subsection{Invertebrate sampling}

Ground beetles were sampled using pitfall trapping. Traps consisted of plastic beakers $(75 \mathrm{~mm}$ in diameter and $100 \mathrm{~mm}$ deep) partly filled with $100 \%$ monopropylene glycol as a killing agent and preservative. To prevent small mammals from entering the traps and to limit damage by livestock, a $15 \mathrm{~mm}$ mesh grid was secured over the trap mouth with a metal staple (Downie et al. 2000). At each sampling location a $16 \mathrm{~m}$ row of nine pitfall traps ( $2 \mathrm{~m}$ inter-trap distance) was established at the beginning of May. The traps were left in situ for a period of four weeks and the sample from each row of 9 traps was collected and pooled in June.

\subsection{Vegetation sampling}

At each sampling location, vegetation height and species composition were measured between June and August each year at two spatial scales: the transect level and the wider patch level.
Using the HFRO sward stick (Barthram 1986) 25 sward heights were sampled within 25 $\mathrm{cm}$ of each side of a transect line corresponding to the line of pitfall traps. Mean sward height (in $\mathrm{cm}$ ), sward heterogeneity (standard error of vegetation height), transect evenness (abundance of the dominant species), transect diversity (Shannon-Wiener index) and transect species richness were calculated.

A map was produced of the vegetation patches in a $30 \mathrm{~m}$ diameter circle centred on the middle pitfall trap. 'Patch' was defined as an area of vegetation of similar species composition and structure, distinct from adjacent vegetation. The plant community of each of the patches was recorded, and 25 or 50 sward heights were measured from each of the main patches. The number of patches, number of plant communities, withinpatch species richness, patch mean sward height, patch vegetation heterogeneity (standard error of patch vegetation height), patch perimeter length and patch height ratio (maximum patch height divided by the minimum patch height) were measured.

\subsection{Physical attributes}

During the pitfall sampling period, four soil cores (6 $\mathrm{cm}$ diameter and $10 \mathrm{~cm}$ deep) were taken at random from each line of pitfall traps and the soil was subjected to standard soil analyses to determine: $\mathrm{pH}, \%$ moisture content, $\%$ organic matter content, phosphorus availability (mg/l) and potassium availability $(\mathrm{mg} / \mathrm{l})$. Information on the soil penetrability (blf/in ${ }^{2}$ ) was collected using a soil penetrometer. In addition the slope angle (degrees), the aspect (degrees from North), and the altitude of each pitfall sampling location were recorded. 
Table 2. Species inventory for the intensive and extensively grazed plots at Kirkton and Sourhope $(E=$ extensive, $\mathrm{I}=$ intensive). The ecological group of each species is provided (see footnote).

\begin{tabular}{|c|c|c|c|c|c|}
\hline Species & Ecological group & $\begin{array}{l}\text { Sour- } \\
\text { hope, } E\end{array}$ & $\begin{array}{l}\text { Kirk- } \\
\text { ton, E }\end{array}$ & $\begin{array}{l}\text { Sour } \\
\text { hope, I }\end{array}$ & $\begin{array}{l}\text { Kirk- } \\
\text { ton, I }\end{array}$ \\
\hline Calathus fuscipes & Medium nocturnal predators & $x$ & - & $x$ & - \\
\hline Cychrus caraboides & Medium nocturnal predators & - & $\mathrm{x}$ & - & $x$ \\
\hline Harpalus rufipes & Medium nocturnal predators & $\mathrm{x}$ & - & - & - \\
\hline Nebria brevicollis & Medium nocturnal predators & $x$ & $\mathrm{x}$ & $x$ & $x$ \\
\hline Patrobus assimilis & Medium nocturnal predators & - & $x$ & - & $x$ \\
\hline Patrobus atrorufus & Medium nocturnal predators & - & $\mathrm{x}$ & - & $x$ \\
\hline Pterostichus adstrictus & Medium nocturnal predators & $x$ & $\mathrm{x}$ & $x$ & $\mathrm{x}$ \\
\hline Pterostichus aethiops & Medium nocturnal predators & $\mathrm{x}$ & $\mathrm{x}$ & $\mathrm{x}$ & $x$ \\
\hline Pterostichus madidus & Medium nocturnal predators & $\mathrm{x}$ & $\mathrm{x}$ & $x$ & $x$ \\
\hline Pterostichus melanarius & Medium nocturnal predators & $\mathrm{x}$ & - & $x$ & - \\
\hline Pterostichus niger & Medium nocturnal predators & $\mathrm{x}$ & $\mathrm{x}$ & $x$ & $x$ \\
\hline Carabus arvensis & Carabus spp. & - & $x$ & - & $x$ \\
\hline Carabus glabratus & Carabus spp. & - & $\mathrm{x}$ & - & - \\
\hline Carabus nemoralis & Carabus spp. & $x$ & $x$ & $x$ & - \\
\hline Carabus nitens & Carabus spp. & - & $\mathrm{x}$ & - & $\mathrm{x}$ \\
\hline Carabus problematicus & Carabus spp. & $x$ & $x$ & $x$ & $x$ \\
\hline Carabus violaceus & Carabus spp. & $\mathrm{X}$ & $\mathrm{x}$ & $x$ & $x$ \\
\hline Amara aenea & Diurnal herbivores & $x$ & - & $x$ & - \\
\hline Amara communis & Diurnal herbivores & $x$ & $\mathrm{x}$ & $\mathrm{x}$ & - \\
\hline Amara familiaris & Diurnal herbivores & $x$ & - & $x$ & - \\
\hline Amara lunicollis & Diurnal herbivores & $x$ & $\mathrm{x}$ & $x$ & $x$ \\
\hline Loricera pilicornis & Collembola specialists & $\mathrm{x}$ & $\mathrm{x}$ & $\mathrm{X}$ & $x$ \\
\hline Notiophilus aquaticus & Collembola specialists & $x$ & - & - & - \\
\hline Notiophilus biguttatus & Collembola specialists & - & $\mathrm{x}$ & $x$ & $\mathrm{x}$ \\
\hline Agonum assimile & Small nocturnal predators & - & $x$ & - & $\mathrm{x}$ \\
\hline Calathus melanocephalus & Small nocturnal predators & $\mathrm{x}$ & - & $\mathrm{X}$ & - \\
\hline Pterostichus rhaeticus & Small nocturnal predators & $x$ & $x$ & $x$ & $x$ \\
\hline Agonum fuliginosum & Small/medium predators & - & $\mathrm{x}$ & $x$ & $x$ \\
\hline Agonum gracile & Small/medium predators & - & - & $\mathrm{x}$ & - \\
\hline Agonum muelleri & Small/medium predators & - & $x$ & $x$ & $x$ \\
\hline Bembidion guttula & Small/medium predators & - & - & $x$ & - \\
\hline Bembidion unicolor & Small/medium predators & - & - & $x$ & - \\
\hline Clivina fossor & Small/medium predators & - & $\mathrm{x}$ & $x$ & $x$ \\
\hline Elaphrus cupreus & Small/medium predators & - & $\mathrm{x}$ & $x$ & $x$ \\
\hline Elaphrus lapponicus & Small/medium predators & - & $\mathrm{x}$ & - & $\mathrm{x}$ \\
\hline Elaphrus uliginosus & Small/medium predators & - & $\mathrm{x}$ & - & $x$ \\
\hline Leistus rufescens & Small/medium predators & - & - & $\mathrm{X}$ & - \\
\hline Pterostichus diligens & Small/medium predators & $\mathrm{x}$ & $x$ & $x$ & $x$ \\
\hline Pterostichus strenuus & Small/medium predators & $\mathrm{x}$ & $\mathrm{x}$ & $\mathrm{x}$ & $\mathrm{x}$ \\
\hline Pterostichus versicolor & Small/medium predators & - & $\mathrm{x}$ & $\mathrm{X}$ & $\mathrm{x}$ \\
\hline Trechus obtusus & Small/medium predators & - & $\mathrm{x}$ & $x$ & $x$ \\
\hline Harpalus latus & Nocturnal herbivores & - & $\mathrm{x}$ & - & $x$ \\
\hline Trichocellus placidus & Nocturnal herbivores & $\mathrm{x}$ & - & - & - \\
\hline Agonum piceum & Insufficient information & - & - & $\mathrm{x}$ & - \\
\hline Bradycellus collaris & Insufficient information & - & - & $x$ & - \\
\hline Carabus granulatus & Insufficient information & - & $\mathrm{x}$ & - & $x$ \\
\hline Elaphrus riparius & Insufficient information & - & $\mathrm{x}$ & - & $x$ \\
\hline Harpalus quadripunctatus & Insufficient information & $x$ & - & - & - \\
\hline Total species richness & & 23 & 33 & 32 & 30 \\
\hline Total carabid abundance & & 1145 & 1207 & 1235 & 1436 \\
\hline
\end{tabular}

These groups correspond to Cole et al. (2002) ecological groups as follows: Medium nocturnal predators - Group 1, Carabus species - Group 2, Diurnal herbivores - Group 3, Collembola specialists - Group 4, Small nocturnal predators - Group 5, Small to medium predators - Group 6, Nocturnal herbivores - Group 7. 


\subsection{Statistical analysis}

The 9 pitfall traps collected at each location were pooled prior to carabid identification. For each sampling year the following measures of diversity were calculated: the number of ground beetle species (S) to measure species richness, BergerParker dominance index (d) to measure evenness and Simpson's diversity index (N2) to measure overall diversity. Magurran (1988) recommends combining diversity indices to obtain a more accurate picture of diversity than simply considering one or two overall diversity indices. Prior to the analyses, diversity indices were log-transformed where required to approach normality of the compared distributions. ANOVAs were conducted (at each research station independently) to determine how year of sampling and grazing regime influenced ground beetle diversity. The 20 new locations sampled in 2004, and the bracken locations sampled in 2003 at Sourhope were omitted from this analysis. Where significant differences were indicated by ANOVA, Tukey's post hoc tests were applied to locate the differences.

While diversity indices provide some indica- tion of the composition of ground beetle assemblages, they provide little information on the ecological structure of the community. To obtain comprehensive information on the ecological makeup of the carabid assemblages at each location, the relative abundance of ground beetle ecological groups - as described by Cole et al. (2002) - was calculated for each sampling location (Table 2). Five species (of the 48 species collected) that lacked sufficient ecological data were omitted from these analyses (Table 2). All omitted species were extremely rare, and consequently it is unlikely that their omission influenced the analyses. Two-way ANOVAs were conducted on the arcsin-transformed data for each research station independently to determine if grazing intensity and year of sampling influenced the ecological makeup of the ground beetle assemblages.

Canonical Correspondence Analysis (CCA) was conducted for each research station independently to determine the principal environmental components driving the ecological assemblage structure. CCAs were conducted on the relative abundance of ecological groups. A total of 20 continuous environmental variables and one categorical variable (Grazing Intensity) were

Table 3. Environmental variables taken into consideration in CCA.

\begin{tabular}{ll}
\hline Environmental variable & Description \\
\hline Moisture & Soil moisture content \% \\
Organic matter & Soil organic matter content \% \\
pH & Soil pH \\
Phosphorus & Availability of phosphorus in the soil (mg/l) \\
Potassium & Availability of potassium in the soil (mg/l) \\
Penetrability & Soil penetrability (blf/in ${ }^{2}$ ) \\
Aspect & Aspect of the pitfall traps (degrees from north) \\
Altitude & Altitude of the pitfall trap location (m) \\
Slope & Slope of the pitfall trap location (degrees) \\
Grazing intensity & Grazing intensity of plot (intensive or extensive) \\
Transect height & Transect: mean sward height (cm) \\
Transect heterogeneity & Transect: standard error of vegetation height \\
Transect richness & Transect: number of plant species \\
Transect evenness & Transect: \% abundance of the dominant plant species \\
Transect diversity & Transect: Shannon-Wiener index of vegetation \\
Patch ratio & Patch: maximum vegetation height divided by minimum vegetation height \\
Number of patches & Patch: number of different vegetation patches \\
Number of communities & Patch: number of different vegetation communities \\
Patch richness & Patch: number of species in patch \\
Patch length & Patch: the total patch edge length \\
Patch heterogeneity & Patch: standard error of mean patch height \\
&
\end{tabular}


considered in the analyses (Table 3 ). Environmental variables were normalised by logarithmic transformation where required. The eight bracken encroached locations at Sourhope were omitted from this analysis due to insufficient vegetation data. A forward selection process was utilised and only variables found to be statistically significant (at the 5\% level) by the Monte Carlo Permutation test were included in the analyses, thus reducing problems associated with multicollinearity (ter Braak \& Šmilauer 2002).

\section{Results}

A total of 2,643 carabids consisting of 33 species were collected from Kirkton and 2,380 carabids consisting of 36 species from Sourhope (Table 2).

\subsection{Influence of management and sampling year on diversity and ecological group}

Two-way ANOVAs (Table 4a-b) indicated that grazing intensity did not influence the species richness (S), evenness (d) or overall diversity (N2) of the carabid assemblages at Kirkton or Sourhope. At Kirkton, the year of sampling had no influence on any of the diversity indices studied, while at Sourhope a significant year effect was found for carabid species richness with sig-
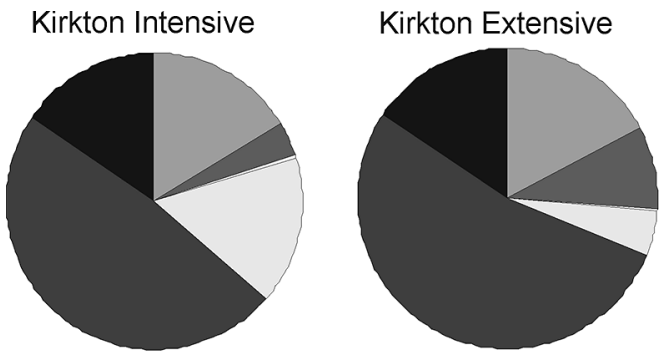

Sourhope Intensive

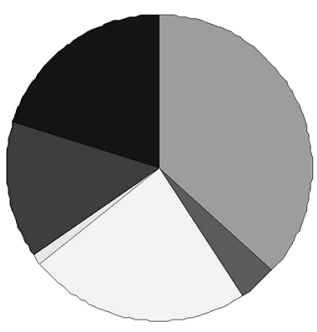

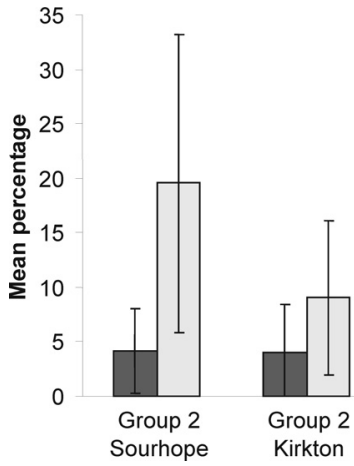

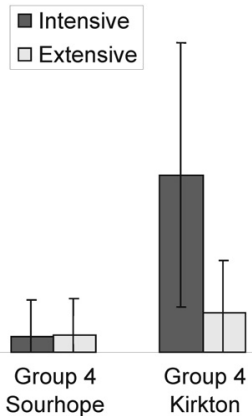

Fig. 1. Mean (+ SD) relative abundance of Carabus species and Collembola specialists (Group 2 and 4, respectively) on intensively and extensively grazed plots at Kirkton and Sourhope.

nificantly more species being recorded in 2003 than 2004 (Table 4b).

At both research stations, large, immobile beetles of the genus Carabus were more abundant on extensively managed plots than intensively managed ones (Table $4 a-b$, Fig. 1). The relative abundance of Carabus species at Kirkton was over two times higher in the extensive plot than the intensive plot, while at Sourhope the difference was even more profound with almost a 5 fold increase in relative abundance between the intensive and extensive plots. This difference was found despite Carabus species being predominantly autumn breeders and hence potentially less active in spring when the samples were taken. $\square$ Functional Group 1

Sourhope Extensive

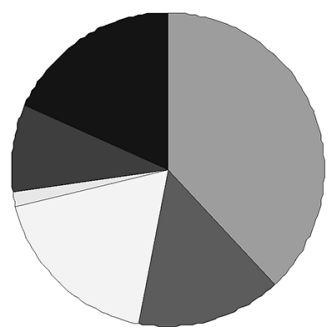

- Functional Group 2

Functional Group 3

Functional Group 4

- Functional Group 5

- Functional Group 6

- Functional Group 7
Fig. 2. The ecological make-up of the intensively- and extensivelymanaged plots at Kirkton and Sourhope. 
Table 4. Results of 2-way ANOVA for ground beetle diversity and relative abundance of different ecological groups at Kirkton (a) and Sourhope (b). Location of significant differences found using Tukey's post hoc tests ( $p$ $<0.05) . \mathrm{n} / \mathrm{a}=$ not analysed due to insufficient data.

a) Kirkton

Index / Group

Species Richness (S)

Berger-Parker (d)

Simpson's (N2)

Medium nocturnal predators

Carabus spp.

Diurnal herbivores

Collembola specialists

Small nocturnal predators

Small/medium predators

Nocturnal herbivores

b) Sourhope

Index / Group

Species richness (S)

Berger-Parker (d)

Simpson's (N2)

Medium nocturnal predators

Carabus spp.

Diurnal herbivores

Collembola specialists

Small nocturnal predators

Small/medium predators

Nocturnal herbivores

Treatment $(\mathrm{df}=1,36)$
$F=1.53, p=\mathrm{ns}$
$F=0.95, p=\mathrm{ns}$
$F=0.93, p=\mathrm{ns}$
$F=0.01, p=\mathrm{ns}$
$F=7.17, p=0.01 \quad($ Ext $>$ Int $)$
$\mathrm{n} / \mathrm{a}$
$F=24.57, p<0.001 \quad($ Ext $<$ Int $)$
$F=1.82, p=\mathrm{ns}$
$F=0.48, p=\mathrm{ns}$
$F=0.08, p=\mathrm{ns}$

Treatment $(\mathrm{df}=1,20)$

$F=0.01, p=n s$

$F=0.62, p=$ ns

$F=0.11, p=$ ns

$F=0.09, p=$ ns

$F=10.75, p<0.005$ (Ext>Int)

$F=0.73, p=$ ns

$F=0.00, p=n s$

$F=0.03, p=$ ns

$F=0.87, p=n s$

$\mathrm{n} / \mathrm{a}$

\author{
Year $(\mathrm{df}=1,36)$ \\ $F=0.26, p=\mathrm{ns}$ \\ $F=2.60, p=\mathrm{ns}$ \\ $F=2.75, p=$ ns \\ $F=2.70, p=$ ns \\ $F=0.53, p=n s$ \\ n/a \\ $F=1.07, p=$ ns \\ $F=4.27, p<0.05(2003<2004)$ \\ $F=3.20, p=$ ns \\ $F=0.12, p=n s$
}

Year $(\mathrm{df}=1,20)$

$F=5.34, P=<0.05(2003<2004)$

$F=0.85, p=n s$

$F=0.33, p=$ ns

$F=0.05, p=n s$

$F=1.35, p=\mathrm{ns}$

$F=2.17, p=$ ns

$F=1.58, p=$ ns

$F=2.51, p=\mathrm{ns}$

$F=1.57, p=n s$

$\mathrm{n} / \mathrm{a}$
The only other ecological group influenced by grazing intensity was Collembola specialists. At Kirkton, the relative abundance of this group was four times lower in the extensively managed than in the intensive plot (Table 4a, Fig. 1). At Sourhope, no difference was observed between the two grazing treatments (Table 4b, Fig. 1).

The relative abundance of functional groups in the pitfall traps appeared to be fairly constant between sampling years with only small nocturnal predators at Kirkton being influenced by sampling year. This group had a higher relative abundance in 2004 than in 2003 (Table 4a, Fig. 1). This indicates that the ecological assemblage structure was relatively consistent between sampling years.

Clear differences were found in the ecological make-up of carabid assemblages at Kirkton and Sourhope (Fig 2). Small nocturnal predators dominated the community at Kirkton, while at Sourhope the community was dominated by medium sized nocturnal predators. Furthermore, small to very small diurnal herbivore species were well represented at Sourhope but largely lacking at Kirkton. Despite differences in the ecological makeup of the assemblages at the two research station, consistent trends in the relative abundance of Carabus species were found between extensively and intensively managed plots (Fig. 2).

\subsection{Influence of environmental factors on the ecological assemblage structure}

CCA for the Sourhope data produced eigenvalues of $0.318,0.18,0.07$ and 0.03 for axes $1-4$, accounting for $26.7 \%, 15.7 \%, 5.9 \%$ and $2.7 \%$ of the total variation in ecological structure, respectively (Fig. 3). CCA for the Kirkton data produced eigenvalues of $0.124,0.070,0.025$ and 0.004 for axes $1-4$, accounting for $22.9 \%, 12.9 \%$, $4.7 \%$ and $0.7 \%$ of the total variation in ecological structure, respectively (Fig. 4). The low eigenvalues were expected, as the ordination was conducted on only seven ecological groups as op- 


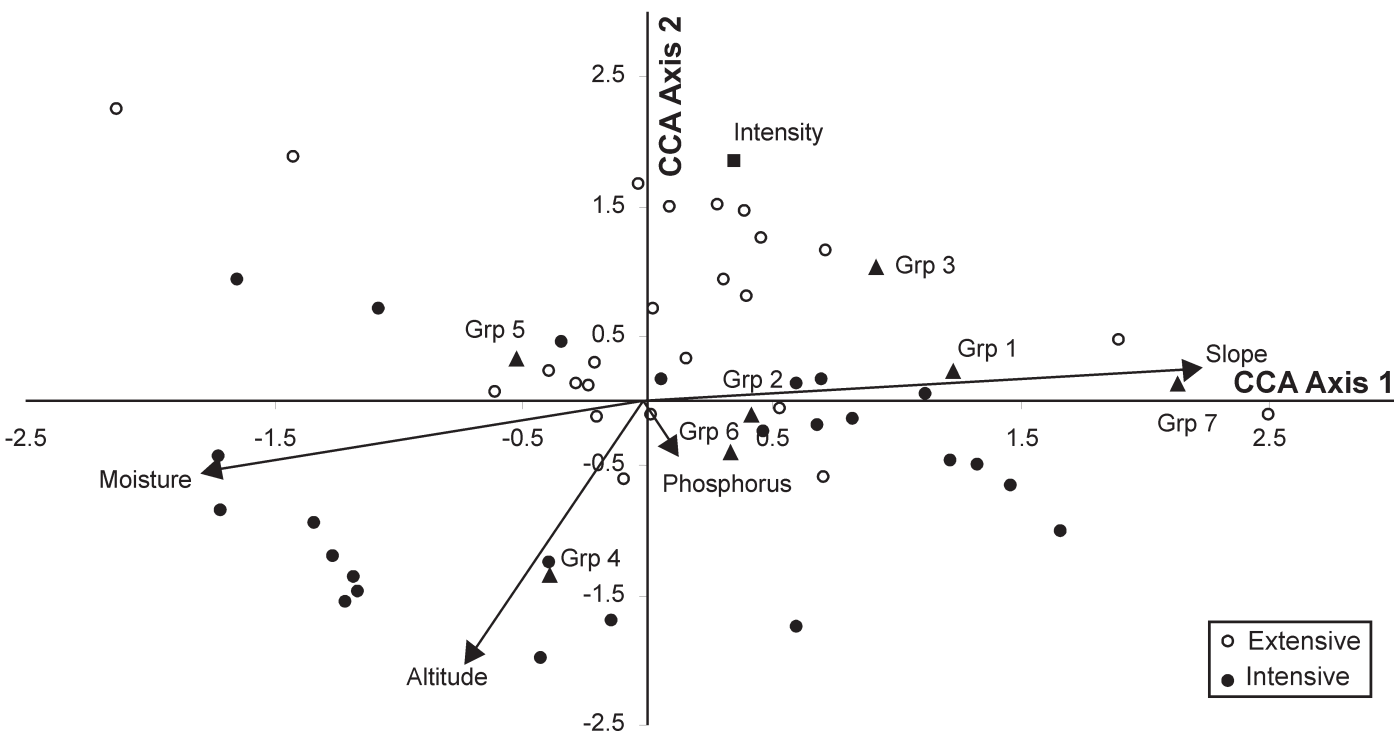

Fig. 3. CCA triplot for the Kirkton ecological-group relative-abundance data showing intensive and extensive sites, carabid ecological groups (black triangles; see Table 2), continuous environmental variables (vectors) and intensity as a categorical environmental variable (black square box near origin). Only environmental factors significant at the $5 \%$ level are included in the graph (see Table 5).

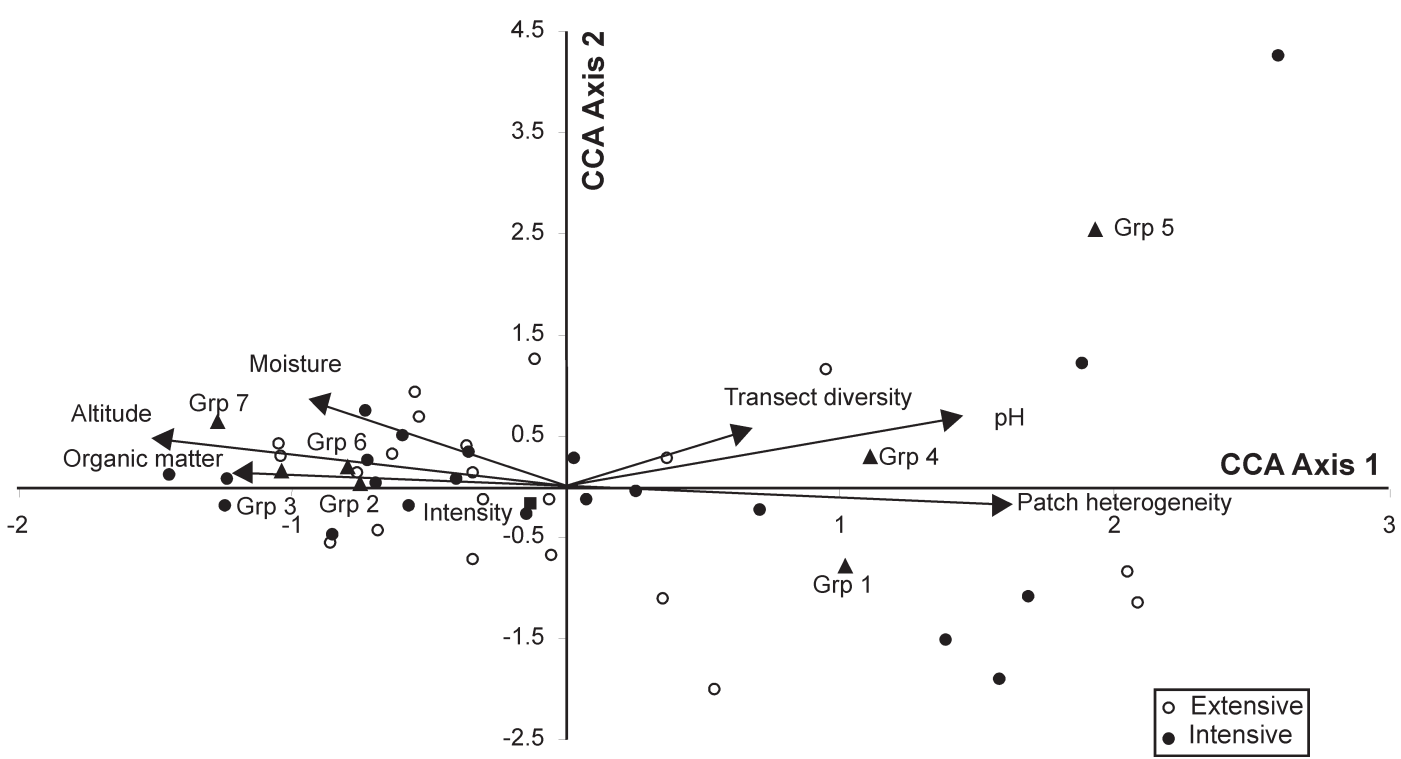

Fig. 4. CCA triplot for the Sourhope ecological-group relative-abundance data showing intensive and extensive sites, carabid ecological groups (black triangles; see Table 2), continuous environmental variables (vectors) and intensity as a categorical environmental variable (black square box up-and-right from the origin). Only environmental factors significant at the $5 \%$ level are included in the graph (see Table 5).

posed to a large number of individual species. For both locations, axes 1 and 2 accounted for most of the variation in the ecological structure of carabid assemblages.
At Kirkton, the CCA showed a clear separation of intensively vs. extensively grazed plots along axis 2 (Fig. 3). At Sourhope, the difference between the intensively and extensively grazed 
Table 5. Influence of environmental variables on carabid ecological assemblage structure as indicated by CCA. Only factors found significant in the Monte-Carlo permutation test $(p<0.05)$ are shown.

\begin{tabular}{lll}
\hline Environmental factor & Kirkton & Sourhope \\
\hline Slope & $F=8.00, p<0.001$ & - \\
Grazing intensity & $F=5.25, p<0.005$ & $F=3.92, p<0.005$ \\
Altitude & $F=5.05, p<0.005$ & $F=12.96, p<0.005$ \\
Moisture & $F=4.37, p<0.01$ & $F=4.92, p<0.05$ \\
Phosphorus availability & $F=3.18, p<0.05$ & - \\
pH & - & $F=4.39, p<0.05$ \\
Organic matter & - & $F=3.21, p<0.01$ \\
Transect diversity & - & $F=2.57, p<0.05$ \\
\hline
\end{tabular}

plots was not so apparent (Fig. 4). The separation of sampling locations along axis 1 was primarily a consequence of altitude. The lower-altitude locations in both the intensively and the extensively grazed plots had higher axis 1 scores than had the higher-altitude locations. At Sourhope, sheep grazing was more intensive at the foot of both plots where the vegetation was more nutritious than on the poorer quality vegetation found at higher altitudes.

At Kirkton, five environmental variables (Slope, Grazing Intensity, Altitude, Moisture and Phosphorus Availability) significantly influenced the ecological structure of the ground beetle assemblage, while at Sourhope six environmental variables (Altitude, Organic Matter, Grazing Intensity, Moisture, $\mathrm{pH}$, Transect Diversity) did so (Table 5). Three environmental variables influenced ecological structure at both research stations (i.e., Grazing Intensity, Altitude and Moisture) indicating the potential of these variables to be used as predictors of ecological structure.

At Kirkton, vegetation attributes did not influence the carabid ecological assemblage structure indicating the importance of soil and topography. At Sourhope, the diversity of the vegetation at the transect level, significantly influenced the ecological structure. At Sourhope, the lower altitude sampling locations on both plots were dominated by Agrostis species (i.e., A. canina and A. capillaris), while the higher altitude locations were dominated by mosaics of Agrostis species (i.e., A. canina and A. capillaris) and Nardus stricta. It is likely that a combination of altitude, soil factors (e.g., soil pH and organic content) and grazing pressure contributed to this difference in vegetation structure.

\section{Discussion}

Grazing intensity in the uplands can influence carabids at both the species and assemblage level (Dennis et al. 1997; Luff \& Rushton 1989). Habitat affinity of different species can differ between various geographical locations. Species described by Thiele (1977) as being strictly woodland species have also been associated with long grass, heath or moorland in the U. K. (Luff 1998). Consequently, findings at the species level are rarely transferable to different geographical locations. Diversity indices, being unrelated to the actual species present, may provide a more robust way of monitoring the influence of agricultural management across different geographical locations. Diversity indices have been widely used in carabid studies (Kromp 1989, Luff \& Rushton 1989, Bhriain et al. 2002, Shah et al. 2003) with many studies indicating a higher carabid diversity in extensively than intensively managed fields (Luff \& Rushton 1989, Blake et al. 1996, Kromp 1989). While the use of diversity indices may be robust, much of the ecological information is lost. By solely looking at the diversity of a community we may risk to oversimplify the data and consequently loose information that may be apparent at a finer scale. The use of ecological groupings could provide a useful way of retaining such information while allowing robust comparisons.

In this study, grazing intensity did not significantly influence carabid diversity but it influ- 
enced the ecological structure, indicating that monitoring at the ecological level was more sensitive than monitoring diversity. Large species belonging to the genus Carabus had a higher relative abundance in extensively managed plots than on intensively managed ones. These findings were consistent not only between sampling years, but also between the two research stations. Blake et al. (1994), Ribera et al. 2001 and Tietze (1985) also found that extensively managed grassland habitats favoured larger carabids, and Cole et al. (2002) found that the abundance of Carabus species was greater in heather moorland and seminatural grassland than on intensively managed grass and arable land. Šustek (1987) found that urbanisation had a significant influence on carabid body size with more urban areas having higher numbers of small species while undisturbed habitats had higher numbers of large sedentary species. It would therefore appear that the relative abundance of large flightless carabids (e.g., Carabus species) might provide a robust indicator of habitat disturbance. It is likely that large, long-living, flightless beetles are favoured by the greater stability in vegetation structure that accompanies extensive grazing practices and are less well adapted to the fluctuating conditions characteristic of intensively grazed sites. Most large Carabus species are autumn-breeders with over-wintering larvae and (at least in Scotland) two-year breeding cycles (Ribera et al. 1999). Immobile species with long-life cycles require resources that are stable over time.

In agreement with the findings of other authors (Ribera et al. 2001, Cole et al. 2002), Collembola specialists had a higher relative abundance in intensively grazed locations at Kirkton when compared to extensively grazed locations. The same trend was not observed at Sourhope. Collembola specialists prefer a more open sward as this facilitates hunting by visual cues. It is possible that intensive grazing resulted in a more open sward structure at Kirkton than at Sourhope hence favouring Collembola specialists. Our ordinations, however, indicated that vegetation characteristics did not influence the carabid ecological structure at Kirkton and grazing intensity and altitude appeared to be the principal environmental factors influencing Collembola specialists. Consequently it is possible that the higher relative abundance of Collembola specialists at Kirkton was related to an increase in the abundance of prey.

The vegetation diversity of intensively managed grassland tends to be more impoverished (both in terms of the number of species and structural diversity) than that of extensively managed grassland (Marriott 2004). This held true for the study sites where vegetation diversity (measured by the Shannon-Wiener index) was richer in the extensively managed plots when compared to the intensively managed plots. It may therefore be predicted that diurnal and nocturnal herbivores would be more abundant in the extensively managed plots. Thomas et al. (2001) found that herbivorous carabids (i.e., Harpalus and Amara species) were associated with the botanically diverse field margins in intensively managed agricultural land, and these species have also been shown to be associated with weed cover in arable crops (Holland \& Luff 2000). Grazing intensity, however, did not significantly influence nocturnal or diurnal herbivores in this study. Herbivorous carabids tend to favour vegetation associated with dung patches (Dennis et al. 1997) and consequently they are likely to have a patchy distribution making accurate sampling difficult.

Despite the ecological structure of the carabid assemblages being quite different at the two locations, changes in the relative abundance of Carabus species between extensive and intensively managed plots were consistent. Monitoring methods that look at the relative abundance of Carabus species are therefore robust and, at least in this study, were more sensitive than diversity indices. There is consensus in the literature that agricultural disturbance adversely influences larger carabids and consequently it is possible that the influence of management on Carabus species could simply be the result of their large size. While size may be a suitable substitute for ecological groupings, and indeed would be far simpler to determine for species not in the original classification by Cole et al. (2002), it is likely that monitoring methods looking simply at size distributions would be less sensitive. For example, it is highly unlikely that methods analysing carabid assemblages simply on the basis of size distribution would have picked up the influence of management intensity on Collembola special- 
ists (Cole et al. 2002, this study). It is therefore suggested that monitoring at the ecological group level should be used as a complementary method of analysing carabid assemblage data as it provides both a more sensitive approach than diversity indices yet the results are potentially robust enough to be transferable to different geographical locations.

Acknowledgements. We thank the staff at Kirkton and Sourhope farm for their invaluable assistance. We are also extremely grateful to Shona Blake for her help and advice, and to Billy Harrison, Elaine McEwan and Ruth Morton for their technical assistance. The Scottish Agricultural College receives financial support from the Scottish Executive Environment and Rural Affairs Department (SEERAD).

\section{References}

Barthram, G. T. 1986: Experimental techniques: the HFRO sward stick. HFRO Biennial Report 19841985. - Hill Farming research Organisation, Edinburgh. 29-30 pp.

Beintema, A. J., Thissen, J. B., Tensen, D. \& Visser, G. H. 1991: Feeding ecology of charadriiform chicks in agricultural grassland. - Ardea 79: 31-41.

Bhriain, N, B., Skeffington, M. S. \& Gormally, M. 2002: Conservation implications of land use practices on the plant and carabid beetle communities of two turloughs in Co. Galway, Ireland. - Biological Conservation 105: 81-92.

Blake, S., Foster, G. N., Fischer, G. E. L. \& Ligertwood, G. L. 1996: Effects of management practices on the ground beetle faunas of newly established wildflower meadows in southern Scotland. - Annales Zoologici Fennici 33: 139-147.

Blake S., Foster, G. N., Eyre, M. D. \& Luff, M. L. 1994: Effects of habitat type and grassland management practices on the body size distribution of carabid beetles. — Pedobiologia 38: 502 - 512.

Cole, L. J., McCracken, D. I., Dennis, P., Downie, I. S., Griffin, A. L., Foster, G. N., Murphy, K. J. \& Waterhouse, T. 2002: Relationships between agricultural management and ecological groups of ground beetles (Coleoptera: Carabidae) on Scottish farmland. - Agriculture, Ecosystems and Environment 93: 323 - 336.

Cook, P. 2004: The impact of the CAP Mid-term Review proposals on the Highlands of Scotland. - La Cañada: Newsletter of the European Forum on Nature Conservation and Pastoralism 18: 9.

Dennis, P., Young, M. R. Howard, C. L. \& Gordon, I. J. 1997: The response of epigeal beetles (Col: Carabidae, Staphylinidae) to varied grazing regimes on upland Nardus stricta grasslands. - Journal of Applied Ecology 34: 433-443.
Diaz, S. \& Cabido, M. 1997: Plant functional types and ecosystem function in relation to global change. Journal of Vegetation Science 8: 463-474.

Downie, I. S., Ribera, I., McCracken, D. I., Wilson, W. L., Foster, G. N., Waterhouse, A., Abernethy, V. J. \& Murphy, K. J. 2000: Modelling populations of Erigone atra and $E$. dentipalpis (Araneae: Linyphiidae) across an agricultural gradient in Scotland. - Agriculture, Ecosystems and Environment 80: 15-28.

Eyre, M. D., Luff, M. L., Rushton, S. P. \& Topping, C. J. 1989: Ground beetles and weevils (Carabidae and Curculionoidea) as indicators of grassland management practices. - Journal of Applied Entomology 107: 508-517.

Galbraith, H. 1989: The diet of lapwing Vanellus vanellus chicks on Scottish farmland. - Ibis 131: 80-84.

Holland, J. M. \& Luff, M. L. 2000: The effects of agricultural practices on Carabidae in temperate agroecosystems. - Integrated Pest Management Reviews 5: 109-129.

Kaspari, M. \& Joern, A. 1993: Prey choice in three grassland birds: reevaluating opportunism. - Oikos 68 : 414-430.

Kromp, B. 1989: Carabid beetle communities (Carabidae, Coleoptera) in biologically and conventionally farmed ecosystems. - Agriculture, Ecosystems and Environment 27: 241-251.

Kromp, B. 1999: Carabid beetles in sustainable agriculture: a review on pest control efficacy, cultivation impacts and enhancement. - Agriculture, Ecosystems and Environment 74:187-228.

Leguen de Lacroix, E. 2003: Fact sheet: agriculture and the environment. - European Commission Directorate General for Agriculture, Brussels.

Lövei, G. L. \& Sunderland, K. D. 1996: Ecology and behavior of ground beetles (Coleoptera: Carabidae). Annual Review of Entomology 41: 231-256

Luff, M. L. 1987: Biology of polyphagous ground beetles in agriculture. - Agricultural Zoology Reviews 2: 237-278.

Luff, M. L. 1998: Provisional atlas of the ground beetles (Coleoptera, Carabidae) of Britain. - Biological Records Centre, Huntingdon.

Luff, M. L. \& Rushton, S. P. 1989: The ground beetle and spider fauna of managed and unimproved upland pastures. - Agriculture, Ecosystems and Environment 25: 195-205.

Magurran, A. E. 1988: Ecological Diversity and Measurement. - Princeton University Press, Princeton.

Marriott C.A., Fothergill, M., Jeangros, B., Scotton, M. \& Louault, F. 2004: Long-term impacts of extensification of grassland management on biodiversity and productivity in upland areas. A review. - Agronomie 24: 447-462.

Niemelä, J., Kotze, J., Ashworth, A., Brandmayr, P., Desender, K., New, T., Penev, L., Samways, M. \& Spence, J. 2000: The search for common anthropogenic impacts on biodiversity: a global network. Journal of Insect Conservation 3: 1-7.

Purvis, G., Fadl, A. \& Bolger, T. 2001: A multivariate anal- 
ysis of cropping effects on Irish ground beetles assemblages (Coleoptera: Carabidae) in mixed arable and grass farmland. - Annals of Applied Biology 139: 351-360.

Ribera, I., Foster, G. N., Downie, I. S., McCracken, D. I. \& Abernethy, V.J. 1999: A comparative study of the morphology and life traits of Scottish ground beetles (Coleoptera, Carabidae). - Annales Zoologici Fennici 36: 21-37.

Ribera, I., Dolédec, S., Downie, I. S. \& Foster, G. N. 2001: Effect of land disturbance and stress on species traits of ground beetle assemblages. — Ecology 82: 11121129.

Rushton, S. P., Luff, M. L. \& Eyre, M. D. 1989: The effects of pasture improvement and management on the ground beetle and spider communities of upland grassland. - Journal of Applied Ecology 26: 489-503.

Shah, P. A., Brooks, D. R., Ashby, J. E., Perry, J. N. \& Woiwod, I. P. 2003: Diversity and abundance of the coleopteran fauna from organic and conventional management systems in southern England. - Agricultural and Forest Entomology 5: 51-60.

Southwood, T. R. E. 1988: Tactics, strategies and templets: - Oikos 52: 3-18.
Šustek, Z. 1987: Changes in body size. Structure of carabid communities. (Coleoptera,Carabidae) along an urbanisation gradient. — Biologia 42: 145-56.

ter Braak, C. J. F. \& Smilauer, P. 2002: CANOCO 4.5 users guide. - Centre for Biometry, Wageningen, the Netherlands.

Thiele, H.-U. 1977: Carabid beetles in their environments. - Springer-Verlag, Berlin.

Tietze, F. 1985: Changes in the ecofaunistic structure of carabid taxocoenoses in agricultural grassland ecosystems by intensified management. - Zoologische Jahrbuch (System.) 112: 367-382.

Thomas, C. F. G., Parkinson, L., Griffiths, G. J. K., Fernandez Garcia, A. \& Marshall, E. J. P. 2001: Aggregation and temporal stability of carabid beetle distributions in field and hedgerow habitats. - Journal of Applied Ecology 38: 100-109.

Whittaker, R. H. 1975: Communities and ecosystems. MacMillan, New York.

Willby, N. J., Abernethy, V. J. \& Demars, B. O. L. 2000: Attribute-based classification of European hydrophytes and its relationship to habitat utilisation. Freshwater Biology 43: 43-74. 